\title{
II Luso-Brazilian Seminar on Scientific Dissemination: Strategies and Reach Analysis to Science Dissemination before and during COVID-19 Pandemic
}

\author{
Alessandra Teles Sirvinskas Ferreira ${ }^{1,2}$ (), Thaís Varandas de Azeredo ${ }^{3}$ (1), \\ Gustavo Henrique Varela Saturnino Alves ${ }^{1,4}\left(\mathbb{D}\right.$, Grazielle Rodrigues Pereira ${ }^{4,5,6} \mathbb{( D}^{(}$, \\ Karine Serpa Franco ${ }^{1,7}$ (D), Suzete Araujo Oliveira Gomes ${ }^{1,3}$ (), Helena Carla Castro ${ }^{1,3}$ (i), \\ Lucianne Fragel Madeira1,3 (i) \\ ${ }^{1}$ Post-Graduation Program in Sciences, Technology and Inclusion, PGCTIn, UFF, Niterói, RJ, Brazil \\ ${ }^{2}$ National Institute on Death Education, INES, Rio de Janeiro, RJ, Brazil \\ ${ }^{3}$ Post-Graduation Program in Science and Biotechnology, PPBI, UFF, Niterói, RJ, Brazil \\ ${ }^{4}$ Post-Graduation Lato Sensu-Specialization in Education and Scientific Dissemination, IFRJ, Mesquita, RJ, Brazil \\ ${ }^{5}$ Post-Graduation Program in Science Education, IFRJ, Nilópolis, RJ, Brazil \\ ${ }^{6}$ Professional Master Course in Education, Management and Diffusion in Biosciences, UFRJ, Rio de Janeiro, RJ, Brazil \\ ${ }^{7}$ Municipal Education Foundation of Niterói, FME, Niterói, RJ, Brazil \\ Email: atsf15@gmail.com, thaisvazeredo@gmail.com,gh_alves@id.uff.br, grazielle.pereira@ifrj.edu.br, \\ karineserpafranco@id.uff.br, suzetearaujo@id.uff.br, hcastro@id.uff.br, lfragel@id.uff.br
}

How to cite this paper: Ferreira, A. T. S., de Azeredo, T. V., Alves, G. H. V. S., Pereira, G. R., Franco, K. S., Gomes, S. A. O., Castro, H. C., \& Madeira, L. F. (2021). II Luso-Brazilian Seminar on Scientific Dissemination: Strategies and Reach Analysis to Science Dissemination before and during COVID-19 Pandemic. Creative Education, 12, 1572-1589.

https://doi.org/10.4236/ce.2021.127119

Received: April 17, 2021

Accepted: July 10, 2021

Published: July 13, 2021

Copyright $\odot 2021$ by author(s) and Scientific Research Publishing Inc. This work is licensed under the Creative Commons Attribution International License (CC BY 4.0). http://creativecommons.org/licenses/by/4.0/

\section{Open Access}

\begin{abstract}
Scientific dissemination plays an important role in spreading scientific and technological information, provoking curiosity, dialogue and interaction. This article aims to analyze the reach and strategies used in 2019 National Week of Science and Technology (2019 SNCT), presented in the II Luso-Brazilian Seminar on Scientific Dissemination: actions in the National Week of Science and Technology, held from 3 to 7 August 2020 on YouTube channel Ciências Sob Tendas. It also aims to discuss the expectations for the upcoming online SCNT. As methodology, data were collected from the speaker's presentation at the event which are representatives from several science centers, museums and others research institutions in Brazil and Portugal. We used Fontoura theme methodology (2011) in data collection and analysis. Therefore, we follow the steps in this analysis model: 1) careful observation of the entire event; 2) selection of the main focus of the speeches; 3 ) delimitation of what was relevant; 4) creation of similar groups; 5) gathering the groups in units of meaning; 6) data tabulation; 7) data interpretation. With this, we highlight the types of activities carried out in 2019 SNCT, research areas contemplated in the activities, actions or strategies to reach the
\end{abstract}


population and the national reach. We conclude that the strategies, developed by museums and science centers, were diversified and adapted to the realities of each location, providing people's training within the specificities of each group. The reach obtained was significant, mainly because they did not stick to the week dedicated to the event, but acted throughout 2019 as well as carried out itinerant actions, prioritizing to reach cities distant from large urban centers. Concerning the COVID-19 pandemic schools, museums and others scientific dissemination places are facing several challenges with online education which had them expand their communication with the public. For that reason, the seminar also provided opportunities for dialogue and the development of strategies for this moment.

\section{Keywords}

Science Dissemination, Technology, Inclusion

\section{Introduction}

Scientific dissemination (SD) plays an important role in spreading scientific and technological information. It may occur through different media such as newspapers, television, science lectures for the lay public, comic books, leaflets, plays with a science and technology theme and even literature of cordel, widespread in northeast Brazil (Bueno, 2010). In addition to these, museums and science centers and other informal education spaces also promote activities for the dissemination of scientific and technological knowledge. These activities seek to involve the visiting public as provoking their curiosity, dialogues and interactions. These strategies intend to highlight the science and technology present in people's culture and day-to-day lives, transporting the visitor to the role of critical thinker of their reality.

Science interferes in society, in several areas and levels: products, production's processes, health, agriculture, livestock, energy's production and many others. This socio-economic growth depends-and is strengthened-on the population's understanding and acceptance of its benefits and applications (Silva et al., 2019). Considering the fast development of scientific-technological knowledge, it is also necessary for a fast assimilation of these innovations by society. Thus, it is crucial to understand the channels through which society has access to scientific information. Citizens who know scientific concepts and their applications can act more consciously, apply technology appropriately, consume it in moderation, have responsibility to prevent diseases and preserve the environment (Silva et al., 2019; Navas et al., 2007).

Society's access to scientific information was put to test in the present scenario of COVID-19 pandemic. Throughout the year 2020, an environment of fear, scientific denialism, conspiracies and hate speech was observed among the world's population. This distrust was promoted mainly by anonymous groups 
and non-specialists who used social networks for political manipulation, dissemination of conspiracy theories and, consequently, to discredit scientific research in the most diverse areas of knowledge (Peters \& Besley, 2020). To meet these positions, it is necessary to invest and defend an education that promotes critical thinking in the population in the face of news from the most diverse media (Oliveira et al., 2012).

So, the understanding that SD is a relevant way to form and inform a critical citizen it is important to study its forms and activities to contribute to the creation of similar initiatives. As a consequence, for this increase the reach of knowledge will also be extended to those less favored, since there is great social inequality in accessing knowledge on equal basis favored by the distribution of museum spaces mostly in large Brazilian cities (Alves et al., 2020; Silva et al., 2019; Rocha \& Marandino, 2017).

Therefore, we believe that actions that contribute to expanding the reach are beneficial for the individual, for society and for the environment. These actions promote a critical citizen attitude and, as more people master scientific and technological knowledge, greater are the possibilities to produce viable and sustainable solutions (Silva et al., 2019).

One of these actions for SD, promoted at national level for the popularization of scientific and technological knowledge, is the National Week of Science and Technology (SNCT, in Portuguese) that happens Every October since 2004. This event is coordinated by the Ministry of Science, Technology, Innovations and Communication (MCTIC, in Portuguese), through the General Coordination for the Popularization and Dissemination of Science. Several places have been collaborating for the SNCT, such as public and private research institutions, universities, museums, foundations for research support, environmental parks, botanical gardens and zoos, state and municipal secretariats (MCTI, 2019).

The SNCT aims to bring the population closer to science and technology themes, especially children and young people, through events with SD activities throughout Brazil. These activities provide contact with scientific knowledge in an accessible language and by provoking curiosity, thus motivating the discussion about science's social implications (MCTI, 2019).

As a result, for SNCT in 2019, the "II Luso-Brazilian Seminar on Scientific Dissemination: actions in the National Week of Science and Technology" was promoted. Held in August 2020, the event was attended by science centers and museums' representatives and other promoters from several research institutions. They presented the activities carried out by their locations in 2019, during the SNCT. In addition, the seminar prompted important debates over the importance of SD and the technological advances necessary to include the population socially, digitally, technologically and also include people with disabilities.

\section{Objective}

This article aims to analyze the reach and strategies used in 2019 SNCT pre- 
sented in the II Luso-Brazilian Seminar on Scientific Dissemination: actions in the National Week of Science and Technology and also, the expectations for the upcoming online 2020 SCNT.

\section{Methodology}

For the accomplishment of this research, data were collected from the presentations made by the speakers at the II Luso-Brazilian Seminar on Scientific Dissemination: actions in the National Week of Science and Technology. They were representants from science centers, museums and others several research institutions in Brazil and Portugal. The event was held from 3 to 7 August 2020, from 10 am to $12 \mathrm{pm}$ on YouTube channel Ciências Sob Tendas, of, who were the speakers at the event.

We used Fontoura's theme methodology (2011) to data collection and analysis. This is a technique, which involves seven stages, used in qualitative research. We therefore follow the steps in this methodology that are: 1) Careful observation of the whole event. As recommended, we watched a first time the whole presentation to observe everything that was said, then we watched it transcribing some speeches and highlighting parts that would require more attention; 2) The selection of the speeches' main focuses. At this moment we highlight the issues that were specifically related to the strategies used, the reach obtained and the strategies for 2020;3) The delimitation of what was relevant; 4) The creation of similar groups; 5) Gathering groups in units of meaning, which were defined in: types of activities carried out at SNCT 2019, the research areas contemplated in the activities, actions or strategies to reach the population, the final reach and, expectations for 2020; 6) Data tabulation; 7) Data interpretation.

The activities research areas were named by speakers, for example, when mentioning that a workshop was about math biology and physics. In other cases, the areas were named according to the title of the activity for example, a workshop about refraction of light and optics was grouped as physics; a workshop about robot programming or Arduino was grouped as technology. The collected data were tabulated and discussed based on bibliography.

Annually, the National Council for Scientific and Technological Development (CNPq, in Portuguese) and the MCTIC make public calls to support projects and events for science dissemination and popularization. In other to be selected the projects must aim Brazil's scientific and technological development through the theme proposed for that year. Another selection criterion is the projects' reach areas, which can fit into one of the two lines according to the number of cities served: Line A-Projects with state or district coverage, with 5 to 20 cities served, varying according to the Federative Unit total of cities; Line B-Projects covering at least 2 cities in their Federative Unit. The seminar's speakers were chosen by the type of project they leaded so all were from Line A.

In 2019, the $16^{\text {th }}$ edition of the SNCT had as its theme: "Bioeconomic: Diversity and Wealth for Sustainable Development" and featured CNPq/MCTIC N ${ }^{\circ}$ 
09/2019. This call included 38 candidates for Line A and 122 candidates for Line $\mathrm{B}$ and, as a result, 101,576 activities were carried out in 1101 cities, with the participation of 521 institutions from all over Brazil.

\section{Theoretical Reference}

Before proceeding with the collected data, we understand how fundamental is to present the understanding of some terms that will be used throughout the text, bringing its concepts and some of its implications. For that, in subsection 4.1, we will discuss SD's educational goal in the dissemination of scientific information, the potentialities of SD, as well as specific and accessible actions and spaces to the population.

From the perception that SD may develop knowledge and understanding about the scientific process in the lay population, we will clarify, in subsection 4.2 , conceptions and relationships between Science and Technology, as protagonists and participants of SD.

Thinking about the role of SD in Science and Technology from an inclusive dimension and social transformation, in subsection 4.3 there is a discussion about inclusion in a broader sense, of public and unrestricted access to scientific knowledge.

Finally, in subsection 4.4, we close with some reflections on the challenges faced with the need to provide school education and SD within the pandemic scenario.

\subsection{Science Dissemination}

Seeking to reach a wide audience with scientific and technological information, scientific dissemination (SD) proposes actions with several resources and techniques to disseminate this information (Bueno, 2010). SD's role is strongly related to the very development of science and technology. For this reason, its goals are educational, seeking to expand knowledge to the lay public through the formation of an informed and critical population (Albagli, 1996).

Thus, several places and activities can be considered promoters of SD, such as: museums and science centers, exhibitions, science fairs, magazines, newspapers, television news and educational materials (Bueno, 2010; Rocha \& Marandino, 2017; Alves et al., 2020). Despite so many paths to SD, the public is the most pertinent element. Therefore, the reformulation of the academic speech to an accessible language must be equivalent to the target audience and the educative intentions. Likewise, it is necessary to pay attention at the way witch these interactions between public and information will occur (Bueno, 2010).

In Brazil, the Department of Science and Technology Dissemination and Popularization, an organ linked to the current MCTI, has as main task to write policies and create programs in this area. One of these policies is the National Science and Technology Week (SNCT), an initiative to create actions in science and technology popularizing (Brasil, 2019; Germano \& Kulesza, 2007). 
Museums and science centers present themselves as examples of "cultural scientific spaces" that seek to popularize science, as well as botanical gardens, zoos, aquariums and planetariums (ABCMC, 2015). These environments promote a non-formal education because it present information to its visitors with a fluid time for learning, through activities that do not follow a progressive method but value the experiences exchanged between individuals. It is worth mentioning that the educational goals for these spaces are well defined by a specialized team with the social commitment to disseminate scientific and technological knowledge (Cascais \& Terán, 2014; Gadotti, 2005).

\subsection{Science and Technology}

Science has been defined in different ways throughout history and even today different definitions and characterizations are by the common or by researchers. Within the original conception, science (episteme, scientia) was understood as "the maximum ideal of human knowledge: the complete and definitive apprehension of an object or process' reality" (Chibeni, 2006, p. 3). This ideal, however, proved to be unattainable and was modified. With the increase of specialization and, consequently, the fragmentation of knowledge, science came to be understood as the knowledge that explains and/or predicts phenomena (Chibeni, 2006).

Chalmers (1993) argues his conception of science as it does not have an exact conception. For him, there isn't a "single science", as different areas of knowledge can produce science. He states that it isn't up to the philosophers to legislate on a concept of Science but claims that each area of knowledge must investigate the validation of its objectives, method of investigation and discovery what it claims to be scientific knowledge or not. Thus, there is no need for a general definition or concept of Science but only the characteristic of science, which is to seek the truth, must be maintained.

Regardless the area, the scientific method chosen, the paradigm followed and defended, science can be understood as the search for knowledge and explanations and the prediction of phenomena, things and people, with a commitment to truth.

This science, following a scientific method, in search of a truth produces scientific knowledge and this, when applied, can bring contributions to the development of society and to technological development.

Paiva (1999), in his study about the concept of technology, brings the Greek origin of the word, explaining that the term Téchné designated the technique or ability to do something, to transform something that is natural into something artificial. Freenberg (2015) adds that, for the Greeks, Téchné is a knowledge that human associates when producing something. Veraszto et al. (2009: p. 21) presents some more synonyms for the term Téchné, such as "producing, building, giving birth, $[\ldots]$ a tool, an instrument", and also brings the meaning of "logy" as a reason, defining technology as "the reason for knowing how to do" and 
"the study of the activity of modifying, transforming, acting".

In Veraszto et al. (2009), we found an analysis of the technology's concept throughout mankind history. For this author, man has developed technology since the manufacture of the first rudimentary instrument to hunt and tear the meat of the animal to eat, two million years ago. This is a reference to the invention of chipped stone blade and, later, the domain of fire. With these tools, man started to develop an intellect, to master reason and to be organized in community. The author also presents another technology developed by man: the intellectual technology of mastering language. Therefore, technology is understood as changes in nature that result in processes, technics, manufactured products or instruments that can improve the living conditions of individuals and his group.

The term "technology" has expanded its meaning and reach. In Silva (2003), several definitions of technology are presented, one in particular is the definition from the Webster's Seventh Collegiate dictionary: the totality of means used to provide the objects necessary for human comfort and sustenance; a system that humanity uses to satisfy its needs and desires. This system involves "equipment, programs, people, processes, organization and purpose" (p. 53).

Silva (2003: p. 63) calls the dissemination of technological knowledge in a collective way "public technological capability" and points it out as fundamental for the development of companies in a certain location.

As this technological capability is considered public domain it leads us to the discussion about social technology, treated by Rodrigues and Barbieri (2008). They discuss the fierce competitiveness between different countries and companies and its devastating consequences for the environment. As they are concerned only with making profit and providing a part of the population with consumer goods, they cause greater social inequality. Within this context, social technology emerges, defined as "replicable products, techniques or methodologies, developed within the community and that represent effective solutions for social transformation" (Rodrigues \& Barbieri, 2008: p. 1070).

In this perspective, technology must be dominated by the public, knowledge, must reach everyone and its products must be produced and made available to the whole society not in an unbridled way and aiming at profit only. Care must be taken to seek for solutions that meet social demand on an equal basis, that are sustainable, that provide more jobs and income and that lead to the autonomy of local producers. For this implementation, there is a movement called "best technology" which seeks to be adapted the technology to a specific purpose as well as combine traditional and advanced technics and it also has a low cost and the participation of the community (Rodrigues \& Barbieri, 2008).

\subsection{Inclusion}

There are tons of discussion on inclusion, especially focusing on people with disabilities. However, when we look at the concept of inclusion, we realize that it is not limited to just this group of people, it involves each and every person who 
is in a situation of unequal conditions and opportunities that can cause deprivation of some kind. That deprivation can be of affect, social, cultural, digital, technological, knowledge, information or communication, briefly anything that can limit full participation on an equal basis with other people. Some authors point to social inequality and low income as factors that contribute to exclusion.

Silva (2009: p. 144) presents social inclusion as "[...] the process by which society adapts in order to include, in all its systems, people with special needs and, at the same time, they prepare to assume its role in Society". However, Rodrigues (2003, apud Silva, 2009) presents inclusion from a perspective of feeling as it is not enough to be in a place physically but must be included in a reciprocal relationship in the act of feeling. Azevedo and Barros (2004, apud Passerino \& Montardo, 2007: p. 4) present inclusion as "the permanent movement in search of equal conditions and opportunities to avoid different situations of deprivation". After their reviews and studies, Passerino \& Montardo (2007), defined inclusion as a permanent social process of rights guarantees, life quality, autonomy and human development for a certain group of individuals, whose access and opportunities are unequal in the society which they live. Such groups oscillate as included and excluded throughout their lives, concomitantly or exclusively.

Therefore, inclusion can be defined as a continuous process of mutual adaptation between individual and society, providing equal opportunities in the most diverse spheres and dimensions.

Today's society is the information's society, the digital's society. Costa (2006) affirms that to be a full citizen, nowadays, it is necessary to be digitally included, to have access to digital media (equipment, internet, software) and to know how to use technological tools with autonomy. These are essential to be able to be informed, learn, communicate, work, participate or belong to the culture that arises from this technological environment and are developing their own identity.

Scientific and technological inclusion, therefore, involves the inclusion of knowledge not only of textual, but the experience. This inclusion is essential to create an egalitarian society. Therefore, actions that promote SD, seeking to reach out of this knowledge should be promoted and encouraged.

\subsection{COVID-19's Impacts on Education and Science Dissemination}

Social activities were cancelled in 2020 in response to the ongoing COVID-19 pandemics including schools, museums and any outdoor experience. As students and teachers were advised to work from home, new challenges surfaced for both. The "distance learning" or "home-based distance learning" requires a quiet and comfortable workspace equipped with technological devices and internet connection. However, the reality presented in Brazil and many other countries is an increasing economic disparity that doesn't allow every child to have a device and/or an internet connection (Petretto, Masala, \& Masala, 2020; Yousefi, Abdollahzadeh, \& Moossavi, 2020).

According to data collected at the end of 2019 by the Brazilian Institute of 
Geography and Statistics (IBGE), 4.3 million Brazilian students did not have access to the Internet that year. Therefore we can infer that they entered the pandemic without internet access. Adding to this is the difficulty in having a computer to attend classes due to the high cost of electronic equipment. Only $43 \%$ of public school's students have one and in the private school this percentage rises to $81.8 \%$ (IBGE, 2019). An alternative for computers is a mobile phone, even so, the research data shows that only $64.8 \%$ of public school's students had a cell phone, while in private school this number is $92.6 \%$.

Besides, living in a busy or abusive house could also impact negatively the students' ability to engage in academic activities (Petretto, Masala, \& Masala, 2020; Yousefi, Abdollahzadeh, \& Moossavi, 2020). According to Armitage and Nellum (2020), research on the Ebola epidemic from 2014 to 2016 revealed that school closures during this period resulted in increased school dropouts, child labor, violence against children as well as higher pregnant adolescents. In May 2020, the Ministry of Women, Family and Human Rights (MMFDH), in Brazil announced that, in 2019, there were 86,800 violations of child and adolescent's rights. Thus, in the first half of 2019, more than 10,000 of these records were sexual violence, more than 34,000 were psychological violence and more than 26,000 were physical violence (MMFDH, 2020). The situation caused by the pandemic is therefore worrying.

Another point to highlight in this discussion is the quality of learning for children with disabilities. This group may need an extra-help for learning like reasonable accommodations, specialized teachers, educators and psychologists. The home confinement limits this kind of professional social contact and accessible learning materials and learning platforms (Petretto, Masala, \& Masala, 2020). The recognition of this reality experienced by people with disabilities is fundamental to develop political strategies that can promote changes. In this sense, it is important to rescue the slogan "Nothing about us without us", used as a central idea by the Brazilian movement for people with disabilities, which aims to enhance their participation in any action (Gorla et al., 2021).

Among schools, SD spaces face these and other challenges about online education. Science museums and other institutions had to reassess and expand their forms of communication with the public as never seen before. Now, they have an opportunity to rethink their mission willing to discover how they can respond to the needs of society as well as be more relevant to different audiences (Freitas et al., 2020). Some negative impacts in the SD area are: scientific denialism, fake news, cuts in funds directed to scientific research, the impossibility of bringing scientific experiments to people, such as science fairs and the difficulty of many scientists and researchers in presenting their findings and knowledge in a clear and accessible way to the general population (Carvalho, 2020; Santos, Almeida, \& Crepaldi, 2020).

Despite this, the scientific area had great visibility, because researchers and scientists have been increasingly invited to participate in interviews, reports and 
lectures to clarify questions about COVID-19, as well as to combat fake news disseminated on social networks (Carvalho, 2020; Santos, Almeida, \& Crepaldi, 2020).

\section{Results and Discussion}

The II Luso-Brazilian Seminar on Scientific Dissemination invited to present their projects and results those who were acknowledged by the Line A support from CNPq as well as guests from Portugal. There were 19 speakers from line A, 2 Portuguese researchers and the MCTI's coordinator for Popularization of Science in 2019. The brazilian States represented were: Pernambuco, Rio de Janeiro, Espírito Santo, Alagoas, Minas Gerais, Maranhão, Rio Grande do Norte, Piauí, Mato Grosso do Sul and Paraná and the portuguese districts were Porto and Vila do Conde. Thus, the event presented experiences in 10 Brazilian states, 20 Portuguese cities that, together, reached about 569,594 people in Brazil and 50,250 people in Portugal.

During the event there were conversations about several actions developed during the 2019's SNCT. Each day a modality proposed by the public call was the guiding theme for presentations: 1) Itinerant actions through Traveling Science, 2) Video Show and Open Doors, 3) Science and Technology Workshops, 4) Science Fairs, 5) Science and technology exhibition. Each day was attended by 3 or 4 speakers and a mediator. The speaker had 15 to 20 minutes and after all the presentations. They answered questions from the participants that were watching on YouTube.

The participants could get previously registered to the seminar and watch the presentation during the hole day but they must fill the attendance list published via Google Forms to receive their certificates per day. There were 297 registrations and an average of 90 daily participations with certificate issuance. The 5 videos transmitted, relating to the 5 days of events, have an average of 300 views until writing of this paper.

\subsection{Actions, Strategies and Reach at SNCT 2019 in Brazil}

Many activities reported by the speakers were not restricted to the SNCT's specific week. There were actions throughout 2019 aiming professional training, stimulating production and participation from teachers and students of basic education before, during and after the event itself. These actions gave priority to continual education, proportioning and expanding SD.

Actions such as courses, workshops, training and lectures for liberal professionals, provide them with tools for a conscious and sustainable professional practice and were carried out by 4 institutions. These initiatives contribute to the inclusion of knowledge and to economic and social development. Encouraging young people, of both sexes, to learn and develop science and technology is essential for the development of a country. Technological knowledge contributes to have more people being able to produce innovations, as well as to update 
themselves according to the demand of the labor market. Without technological knowledge, the production and manufacturing process are stagnant and impaired (Silva, 2003).

In order to reach inland cities and stimulate interest in scientific knowledge, 10 museums and city centers, in 2019, held SD, through several actions, at SNCT. These activities were mostly led by professionals from major cities but there were also some cases of scientists and researchers from the region to value the local production and to serve as an example and motivation for people from those places. According to Savage (2018), when presenting professionals to whom people identify by their similarity in origin or other specific characteristics, there is an increase in the public's interest in what is being treated. This happens because there is a change in perspective, a proof that scientific and technological research is also possible to be achieved by that group.

The same was done to encourage girls to participate in science. Five (5) speakers reported courses, workshops and lectures about "Girls in Science". UNESCO data in 2017 shows that only $28 \%$ of researchers on STEM (science, technology, engineering and mathematics) are women. This occurs, often, due to an internalized culture, in which there is a mistaken understanding that an exact area is only suitable for males (Savage, 2018). In order to change this situation SNCT 2019 in its public call, included the obligation to address the issue.

Besides the usual requirement to prioritize activities for students and teachers of basic education, in 2019, the reach of minority groups as indigenous and quilombolas, was added to the public call. At the event 4 speakers reported carrying out actions with these groups such as activities, workshops, courses and lectures valuing and respecting their culture and knowledge. These actions with minority groups contribute to social inclusion, by bringing academic knowledge to them and, also, by emphasizing the value of their own culture, specificities and knowledge. Thus, as Veraszto et al. (2009) affirm, the technology involves techniques and processes used in the performance of an activity or the production of equipment, as well as in the development of instruments useful for daily tasks. Therefore, much of the knowledge of these groups is characterized as technology and there is a rich scientific knowledge in their traditions. For Rodrigues and Barbieri (2008), society benefits when there is an appropriation of technology by the Community that integrates the most modern with the traditional, empowering individuals and, thus, enabling the sustainable economic development of a location and country.

Activities involving technology, biology and physics were the most recurrent among the presentations. There were 14 speakers reporting activities on technology, 12 on biology and 9 on physics. Arts had a good representation in the activities, as 10 speakers performed activities involving it in some aspect. These data may be related to the fact that since 2011 there was an incentive to students' skills, based on the needs of the market and their demand for workers imaginative, critical and that think differently from the traditional to be able to innovate. 
For this reason, the term STEM was added an A, for Art, and became STEAM (Maeda, 2012).

Other areas covered in the activities were: mathematics (6); archeology (3); astronomy (7); history (3) and languages (4). The absence of geography may happen because there is a correlation between astronomy and archeology with geography, physics and history and, thus, it could be thought that there is this representation within those areas, but not with a specific focus on geography itself. These data make us reflect on the concept of science and technology internalized by the academy. Often, we understand that the human's areas do not have or produce science and technology.

However, as we saw, in the theoretical review, science and technology are not restricted to exacts' subjects. According to the concept previously defined, science is the search for knowledge with a commitment to the truth (Paiva, 1999). Also, technology is a process, technique, production, program, system and instruments that help human beings (Veraszto et al., 2009). Therefore, epistemologically, there is no reason for the low representativeness of these areas in SNCT activities. Another possible reason for this result is not knowing how to articulate these areas within science and technology, in an attractive way, to reach the target audience. As we could see at the seminar, most of those responsible for organizing SNCT's activities, came from exacts' subjects (15) and biology (14) but only 4 of them were trained in the human's areas.

Perhaps, inclusion should be discussed here as the inclusion of different areas, the equalization of different knowledge. Scientific knowledge is widely disseminated through letters; all human, scientific and technological evolution has a historical trajectory that needs to be highlighted so that a scientific practice does not ignore the possible consequences of certain innovations. Philosophy and sociology should be present at all of these events, dealing with ethics and morals of scientific and technological practice, the inclusion of minority groups in scientific production, and the access to technological resources, by those who need them most.

With that said the inclusion of people with disabilities was mentioned as an activity carried out by one speaker and, mentioned by a second speaker, in response to a question about accessibility. We found that there is a difficulty in providing accessibility during these events. Some reasons pointed out by the one who answered the question were 1) the fact that the event's workers are volunteers, students and teachers, and that there is a high switch among them, so there is no time to train people to provide communicational accessibility; 2) the attempt to use an automatic translation device for sign language was not effective because the artificial intelligence translates without considering the context and, often, did typewriting (writing the word with a manual alphabet) because there were no signal information corresponding to a specific term; 3) physical accessibility may vary depending on the space and location of the traveling activities' destination. 
These data make us reflect on inclusion, which involves offering opportunities and access to information on an equal basis and how there is, even today, the exclusion of access to knowledge and, consequently, an inequality of opportunities. In the information age, in which we live, the gaps in knowledge can be, and often are, limiting opportunities for work, studies and access to certain environments (Rodrigues \& Barbieri, 2008). The objective of SD is to bring knowledge to all, providing access to all, without distinction therefore accessibility must be thought out and provided in the institutions' activities.

\subsection{Luso-Brazilian Correlations}

The seminar was attended by two representatives from University of Porto in Portugal. Their annual SD event, entitled Science and Technology Week (SCT, in portuguese), takes place every year in November. During SCT, institutions, universities, museums and schools open their doors and offer workshops, visits to laboratories, exhibitions, scientific tours, lectures and film screenings for the general population.

According to the speakers, travelling activities are not carried out. There are 20 scientific centers distributed in different cities which, when requested, send scientists and other professionals to schools to give lectures, activities or workshops, preferably those places far from the scientific centers. Still, to ease the access for school groups to those spaces there are some transports are available through prior appointment. Nearly 50.250 people were reached throughout 2019.

Science fairs are held by each school, in every city in the country. This reality differs from Brazil, as many cities still don't hold science fairs as in general, a higher education institution is responsible for organizing them. Among Brazilian speakers, 10 speakers reported having developed science fairs and exhibitions in 2019. There were reports that, after these events, 15 new cities started to develop and hold their own science and technologies fairs. An action, reported by a Brazilian speaker, was to leave, in the cities, where the SNCT was held, some of the materials used so that they can make use of it and continue the dissemination of knowledge, as the places have few resources for the acquisition some equipment. Therefore, encouraging scientific centers to support city initiatives can be a strategy to be followed.

Many of Portugal's actions are similar to those in Brazil's SNCT: workshops (13 Brazilians reported offering), lectures (12), film shows (7), exhibitions (12) and, Open Doors (6). As in Portugal, some Brazilian institutions have reported providing transportation for scheduled groups to participate in the events.

As to training and qualification courses for teachers of basic education, Portugal reported offering the courses remotely, and, from the Brazilian speakers, 4 said they offered in person and remotely. In addition, 8 Brazilian speakers reported offering training and qualification courses, for students of basic education (6) and, for professionals (4). 


\subsection{Prospects for SNCT in a Pandemic Era}

The year 2020 brought a new challenge: how to carry out SNCT during a pandemic? This question, although not on the agenda of the Seminar, was addressed by the participants through the online chat. As the world faces the scenario of social distance, strict rules regarding contact and interaction, SD's actions need to be rethought. SNCT's actions always stand out for visitor's interaction with scientific activity, for dialogue with the activities' explainers, for the face-to-face actions in different spaces such as squares, beaches, schools, museums, universities and laboratories.

With that said, all the activities and experiences presented in the seminar and in this paper took place before the coronavirus pandemic started in Brazil and Portugal. The main discussion proposed for the seminar didn't involve activities for this unusual period. However, the topic was addressed many times in other to debate ideas and solutions. There were two speakers that pointed out that they still had difficulties in devising and implementing a strategy, but they were open to suggestions and other twelve of them proposed the use of a virtual environment. Among the planned actions were: lectures through Lives (4 speakers have already started and 8 intend to), videos of activities and workshops with science experiences to do at home or activities to identify these science and technology at home (11), fair and virtual science show (3), $360^{\circ}$ virtual tour presenting the scientific spaces' exhibitions and activities (3), SD through social networks (3), Podcast (2), dialogues between scientists and the public in a virtual way (2), training and qualification courses for teachers and students in the EAD format (Distance Education) (2), virtual games and online movie shows (2). There were also strategies for a possible flexibility mentioned by 5 speakers. In all of them, were activities in small groups with the distribution of individualized hygiene kits.

As to Portugal, which had already started the first flexibilization period by the time of the seminar, the speakers could give more detailed ideas and experiences for this time. They have been carrying out activities with previous scheduling for small groups, delivering personal hygiene kits and, reducing the number of film sessions per day, as well as its auditorium capacity. In addition, they were still using virtual activities such as concerts and television programs.

Considering all the ideas presented for the upcoming online SNCT, the Luso-Brazilian Seminar was considered a positive environment that could provide opportunities for dialogue and exchange of experiences which helped others to develop proper strategies for moments like the current one.

It is not known for sure what the reach and impact of these proposals will be, and they have not yet found a solution to reach people who do not have access to the internet. This a fact that leads us to the exclusion of knowledge and social exclusion caused by the poor distribution of income in Brazil. As Costa (2006) states, the lack of access to equipment and resources triggers a process of maintenance and, even, of widening social inequalities. In this pandemic period, the 
challenge of bringing knowledge on an equal basis has not yet been presented with a solution. We expect that in the future, research can be carried out to understand the impact of this lack of inclusion in society.

Thusly, compiling the result found in the paper it is possible to highlight some topics. The first one is that many activities reported by the speakers happened through 2019 and the first months of 2020 and not only on SNCT's specific week in October. This period also corresponds to the moments before the coronavirus pandemic started in Brazil (Brasil, 2020). We reaffirm that these activities contribute to the inclusion of knowledge among young people, inland cities' population, young girls and minority groups as indigenous and quilombolas. These actions with minority groups contribute to social inclusion and emphases the value of their own culture, specificities and knowledge. However, the same cannot be said for the inclusion of people with disabilities which was only mentioned by one speaker and focused on deaf inclusion.

When it comes to compare the experience in SD in Portugal and Brazil's science and technology week there are more differences in organization than in activities. For example, Portuguese museums rarely go to schools with activities but encourage schools to do their own science fair.

Lastly, the speakers discussed how to carry out SNCT during a pandemic as their actions always stand out for visitor's interaction with scientific activity. The majority intend to use virtual environment in different forms but the Portuguese speakers were also considering a flexibilization period for the isolation and may open their doors to visitors with some security rules.

\section{Final Considerations}

We conclude that the strategies developed by museums and science centers were diversified and adapted to the realities of each location, providing training for people within the specificities of each group. This was seen as positive and made easier the process of caching interest in the actions presented.

The reach obtained was significant, mainly because they did not stick to the week dedicated to the event, but acted throughout 2019, as well as for carrying out travelling actions, prioritizing to reach cities distant from large urban centers. This type of action provides more people with having access to scientific and technological knowledge, stimulating the search for knowledge and contributing to the inclusion of individuals.

We understand that Brazil can follow the example of Portugal, encouraging the development of Science Fairs and Exhibitions by schools of basic education, with the support of institutions in strategic places. In this way, the actions can have a greater reach and the task of carrying out SD will be distributed more equitably.

We understand that this study has some limitations because the results are perceptions obtained through each speech, which may not show the reality. One of the reasons is that each speech time was from 15 to 20 minutes so the activi- 
ties and workshops were not described in detail, most of them just named their title or area. Another limitation within the study was the fact that there were themes for each day of the Seminar; therefore, the speakers may not have mentioned some of their actions because it was out of the theme for the day in question. Thus, a more depth study on how the activities and the topics were carried out may be valid to ascertain whether or not there is a greater range of areas treated within them.

It is also known that, with the pandemic, the year 2020 brought great challenges for SNCT's organizers. In this matter studies on how activities were carried out, their reach and results are important to understand how this whole process took place and to ascertain what actions and strategies impacts were developed.

\section{Conflicts of Interest}

The authors declare no conflicts of interest regarding the publication of this paper.

\section{References}

ABCMC (2015). Centros e museus de ciência do Brasil 2015. Rio de Janeiro: Associação Brasileira de Centros e Museus de Ciência: UFRJ. FCC. Casa da Ciência; Fiocruz. Museu da Vida.

Albagli, S. (1996). Divulgação científica: Informação científica para a cidadania? Ciência da Informação, 25, 396-404.

Alves, G., Fragel-Madeira, L., de Azeredo, T., Castro, H., Pereira, G., \& Coutinho-Silva, R. (2020). Low-Cost Scientific Exhibition: A Proposal to Promote Science Education. Creative Education, 11, 760-782. https://doi.org/10.4236/ce.2020.115055

Armitage, R., \& Nellums, L. B. (2020). Considering Inequalities in the School Closure Response to COVID-19. The Lancet Global Health, 8, e644.

https://doi.org/10.1016/S2214-109X(20)30116-9

Brasil, M. SNCT (2019). 17a Semana Nacional da Ciência e Tecnologia. https://semanact.mcti.gov.br

Brasil, Ministério da saúde (2020). Linha do tempo coronavírus. https://coronavirus.saude.gov.br/index.php/linha-do-tempo

Bueno, W. C. (2010). Comunicação científica e divulgação científica: Aproximações e rupturas conceituais. Informação \& Informação, 15, 1-12. https://doi.org/10.5433/1981-8920.2010v15nesp.p1

Carvalho, J. (2020). Divulgação científica em tempos de pandemia. Jornal do Campus, USP, São Paulo: Brazil.

http://www.jornaldocampus.usp.br/index.php/2020/10/divulgacao-cientifica-em-temp os-de-pandemia

Cascais, M. G. A., \& Terán, A. F. (2014). Educação formal, informal e não formal na educação em ciências. Ciência em Tela, 7, 1-10.

Chalmers, A. F. (1993). O que é ciência afina? Tradução: Raul Filker, Editora Brasiliense.

Chibeni, S. S. (2006). Algumas observações sobre o "método científico".

https://www.unicamp.br/ chibeni/textosdidaticos/metodocientifico.pdf 
Costa, L. F. C. (2006). Inclusão Digital: Conceitos, modelo e semânticas. Intercom Sociedade Brasileira de Estudos Interdisciplinares da Comunicação, XXIX Congresso Brasileiro de Ciências da Comunicação.

Fontoura, H. A. (2011). Tematização como proposta de análise de dados na pesquisa qualitativa. In Formação de professores e diversidades culturais: Múltiplos olhares em pesquisa (pp. 61-82). Niterói: Intertexto.

Freenberg, A. (2015). O que é a Filosofia da Tecnologia? https://www.sfu.ca/ andrewf/books/Portug O que e a Filosofia da Tecnologia.pdf

Freitas, T. P. R. de, Silveira, J. B. A., Costa, P. M. M. da, Miceli, B. S.., \& Rocha, M. B. (2020). Museus de ciências em tempos de pandemia: uma análise no instagram do museu da vida. Revista Práxis, 12. http://revistas.unifoa.edu.br/index.php/praxis/article/view/3483

Gadotti, M. (2005). A questão da Educação Formal/Não-Formal (pp. 1-11). Institut International Des Droits De L'Enfant.

Germano, M. G., \& Kulesza, W. A. (2007). Popularização da Ciência: Uma revisão conceitual. Caderno Brasileiro de Ensino de Física, 24, 7-25.

Gorla, J. A., Fagá, M. A. P., Martins, L. C. M., Costa, J. D., Ribeiro, G. S., Campos, C. A., Carrijo, D. C., Lorenzo, V. R., \& Melo, D. G. (2021). Comunicação social e divulgação científica em tempos de pandemia: Relato de experiência do grupo "Cuidado Sem Limites". Cadernos da Pedagogia, 15, 129-138.

IBGE Instituto Brasileiro de Geografia e Estatística (2019). Síntese de Indicadores Sociais 2019. https://www.ibge.gov.br/estatisticas/sociais/populacao

Maeda, J. (2012). STEM to STEAM: Art in K-12 Is Key to Building a Strong Economy. Edutopia.

https://www.edutopia.org/blog/stem-to-stem-strengthens-economy-john-maeda

MCTI (2019). O que é a Semana Nacional de Ciência e Tecnologia? https://semanact.mcti.gov.br/o-que-e-a-semana-nacional-de-ciencia-e-tecnologia

MMFDH. Ministério Da Mulher, Da Família E Dos Direitos Humanos (2020). Dados e Indicadores sobre Crianças e Adolescentes. https://www.gov.br/mdh/pt-br/navegue-por-temas/crianca-e-adolescente/dados-e-indi cadores

Navas, A. M., Contier, D., \& Marandino, M. (2007). Controvérsia científica, comunicação pública da ciência e museus no bojo do movimento CTS. Ciência \& Ensino, 1.

Oliveira, M. V. et al. (2012). Uma discussão acerca do que é fazer ciência: Algumas considerações sobre comunicação e divulgação científica para a promoção da saúde. Revista de Ciências da Saúde, 24, 53-62.

Paiva, J. E. M. (1999). Um estudo acerca do conceito de tecnologia. Educação e Tecnologia, 4, 5-9.

Passerino, L. M., \& Montardo, S. P. (2007). Inclusão social via acessibilidade digital: Proposta de inclusão digital para pessoas com necessidades especiais. Revista da Associação Nacional dos Programas de Pós-Graduação em Comunicação.

Peters, M. A., \& Besley, T. (2020). Education and the New Dark Ages? Conspiracy, Social Media and Science Denial. Contemporary Issues in Education, 40, 5-14. https://doi.org/10.46786/ac20.3082

Petretto, D. R., Masala, I., \& Masala, C. (2020). School Closure and Children in the Outbreak of COVID-19. Clinical Practice \& Epidemiology in Mental Health, 18, 189-191. https://doi.org/10.2174/1745017902016010189

Rocha, J. N., \& Marandino, M. (2017). Museus e centros de ciências itinerantes: 
Possibilidades e desafios da divulgação científica. Edicc, 3, 49-58.

Rodrigues, I., \& Barbieri, J. C. (2008). A emergência da tecnologia social: Revisitando o movimento da tecnologia apropriada como estratégia de desenvolvimento sustentável. Revista Administração Pública, 42, 1069-1094. https://doi.org/10.1590/S0034-76122008000600003

Santos, A. C. O., Almeida, D. R. B., \& Crepaldi, T. A. A. T. S. (2020). Public Communication and Scientific Dissemination in COVID-19 Times: Actions Develop at the Federal Unibersitu of Uberlãndia-Brasil. Revista Espanola de Comunicacion en Salud, 11, S279-S292.

Savage, N. (2018). Expanding the Reach of Science. Nature, 562, S10-S11. https://www.nature.com/articles/d41586-018-06833-Z https://doi.org/10.1038/d41586-018-06833-z

Silva, A. C. S., Lorenzetti, L., \& Silva, C. S. (2019). Divulgação Científica em um Museu de Ciências: Um estudo de público tendo como foco as famílias visitantes. Revista de Ensino de Biologia da SBEnBio, 12, 36-53. https://doi.org/10.46667/renbio.v12i1.183

Silva, J. C. T. (2003). Tecnologia: Novas abordagens, conceitos, dimensões e gestão. Revista Produção, 13, 50-63. https://doi.org/10.1590/S0103-65132003000100005

Silva, M. O. E. (2009). Da Exclusão à Inclusão: Concepções e Práticas. Revista Lusófona de Educação, 13, 135-153.

Veraszto, E. V., Silva, D., Miranda, N. A., \& Simon, F. O. (2009). Tecnologia: Buscando uma definição para o conceito. Prisma, Porto, 8, 9-46.

http://hdl.handle.net/20.500.11959/brapci/66904

Yousefi, M., Abdollahzadeh, M., \& Moossavi, S. (2020). Equity in Science Education and Disseminations: Lessons Learned during COVID-19 Pandemics. Authorea Preprints. https://d197for5662m48.cloudfront.net/documents/publicationstatus/41290/preprint pdf/0f1b0023899540bfbabdc023a52eb403.pdf 